\title{
The Potential Use of FinTech Developments in Takaful
}

\author{
Hafidh Abdulla Hemed
}

Arwa Abubaker Abdullah Alamoudi

Anas Abdulkadir Abubakar Al Qassim

Bandar Mohammed Saif Qasem

\section{Institute of Islamic Banking and Finance, International Islamic University Malaysia (IIUM), Malaysia}

\begin{abstract}
Despite the increasingly important role that fintech play in the takaful industry, academic research in this area is quite limited. The overall aim of this paper it thus to explore the potential use of fintech in the Islamic insurance industry, especially in terms of its opportunities and challenges. Specifically, big data analytics and roboadvisory were explored and how takaful operators might incorporate them for better customer experience and gathering competitive intelligence. To remain competitive in a fast changing business environment, takaful operators need to identify and adopt fintech that could influence positively customer experience and optimise cost efficiency. This paper reviews the literature on big data analytics and robo-advisory, aiming to shed the light on the barriers and benefits of harnessing these technological advancements for takaful operators.
\end{abstract}

Keywords: Fintech, Takaful, Big Data, Robo-advisors, Artificial intelligence 


\section{Introduction}

Takaful is an insurance concept where members of a certain scheme voluntarily agree to insure each other. Takaful is a contract "whereby a group of participants agree among themselves to support one another jointly for the losses arising from specified risks" (IFSB, 2009, p. 2). Each member contributes voluntarily to a pool which is used to cover other members in case unforeseen calamity causing economic loss. The primary distinguishing feature of takaful from conventional insurance is that takaful is based on voluntary contributions to the risk pool - the pool of funds used to insure claimants (Hassan and Mollah, 2018). Islamic scholars found that conventional insurance is a sale of risk protection to a policyholder because of two main reasons:

Firstly, the exchange of a premium payment "today" for insurance "tomorrow" is akin to an exchange of a sum of funds today for a different amount of funds tomorrow. Such money exchange is prohibited under Islamic jurisprudential law as it is considered as riba (riba al-buyu'), that is, a usurious sale contract (Bekkin, 2007). The rule is supported by various Prophet Muhammad's sayings (hadith). The elaborate reasoning underlying this rule extends beyond the scope of this study, but it can be said is that riba al-buyu' is prohibited in order to achieve more equitable financial dealings. Muslim jurists argued that insurance premiums are exchanged for compensation, and this may involve riba since these two sums are not equal (Iqbal, 2005).

Secondly, the uncertainty (gharar) of insurance is deemed to be excessive due to the ambiguous nature of future events and likelihood of perceived risks that may occur. Islamic scholars argue that high level of uncertainty in insurance policy leads to gambling (maysir) because of its structural similarity to gambling (Bekkin, 2007; Iqbal, 2005; Kadirov, 2021; Saputra et al., 2017). By its very nature, insurance is a risk transfer mechanism, where a party exchange its uncertainty for certainty. The concept of exchanging uncertain loss (claim) with certain loss (premium) is deemed as unfair according to the Islamic law, because one party has gains at the expense of the other party (Iqbal, 2005).

Takaful (Islamic insurance) offers an alternative form of insurance in which the insurer helps policyholders to provide loss protection service for each other (Kader et al., 2014) in a co-operative risk-sharing manner. When financial schemes do not impose bilateral obligations, the presence of riba and maysir cited above become irrelevant. That is, since parties are engage in a financial scheme by choice and out of good will, the ideas of fairness (as it relates to riba) and friction due to uncertainty (as it relates to maysir) are no longer a concern.

\section{Models of Takaful}

There are three commonly used models of takaful that governs takaful operations: mudharaba, wakala, and wakalah-mudharaba waqf model (Malik and Ullah, 2019). The takaful operator (TO) receives a fixed agency fee or share of investment profit, depending on the type of underlying contracts (Hassan and Mollah, 2018).

Under a mudharaba model, the TO is expected to make profit only by ensuring that the total share of investment profit and/or underwriting surplus it may receive is greater

International Journal of Management and Applied Research, 2021, Vol. 8, No. 2 
than the expenses of managing takaful operation (IFSB, 2009). A loss or deficit may occur in the case where the total contribution is lower than the total cost of claims (Malik and Ullah, 2019). In the event of deficit or a periodic deficiency that exceeds the amount of any accumulated reserves, the deficiency shall be borne by shareholders who should provide adequate capital backing in the form of interest-free loan (qard facility), and the shareholders will be repaid when there is surplus in future investment (IFSB, 2009).

On the other hand, the TOs under wakalah and waqf models receive wakalah fee. According to IFSB (2009), the wakalah fee is typically a percentage of the contributions paid, and it must be pre-agreed and clearly stated in the takaful contract. The wakalah fee consists of agent's remuneration, distribution cost, and administration expenses (Hassan and Mollah, 2018) and also a margin of operational profit to the TO (IFSB, 2009). A takaful operator may set a high wakalah fee at the beginning or may lower the wakalah fee as its membership increases over time (Malik and Ullah, 2019). One major disadvantage of using wakalah fee is that, principal-agent problem may arise since TOs might be motivated to earn more wakalah fee than to work in the best interest of the principal (Malik and Ullah, 2019) because the TO does not directly share the risk borne by the takaful fund and TO is not responsible for any investment loss (IFSB, 2009). Moreover, the appointment of TO by shareholders rather than by participants raises the issue of conflicts of interest (IFSB, 2009).

Typically, a takaful operator manages participants' risk fund, a fund that is used to cover claims, and also investment fund where shareholders provide seed capital, appoint management and gain profits from underwriting. This fund is then put into a Shariah-compliant investment, and the surplus of the investment goes to the participants (Hassan and Mollah, 2018). Such fund separation allows the TO to draw money from the risk fund to support its insurance operations, while leaving the investment fund intact unless it experiences investment losses (Kader et al., 2014). However, the lack of representation for the takaful participants and information asymmetry may cause TO to favour shareholders at the expense of the takaful participants' interests (IFSB, 2009).

\subsection{The operating cost of takaful}

The takaful industry is relatively young and it competes with conventional insurance companies. Takaful operators need to be more creative and strategic in order to stay competitive. The relatively limited Shariah-compliant investment opportunities, in addition to the comparatively low market liquidity for Islamic securities when compared to conventional financial markets, could add downward pressure on reported annual profits (Kader et al., 2014). For instance, takaful operators are not permitted to invest in haram industries such as alcohol, pork-related food manufacturing, and gambling activities. It is therefore not easy for takaful operator to maximise profit by increasing returns on invested assets or raising premium rates (Kader et al., 2014), since premiums are pre-defined in the contract. It is thus crucial for takaful operator to focus more on minimising operating cost instead of maximising profit.

One possible reason for high cost lies in marketing, namely in compensating intermediaries and educating potential customers. Intermediaries are paid with high commissions (Malik and Ullah, 2019), especially at the early stage of TO

International Journal of Management and Applied Research, 2021, Vol. 8, No. 2 
establishment, which ultimately trickle down to the participants who pay high premiums to accommodate these costs (Archer et al., 2011). Furthermore, if a TO has underwritten losses, the compensation for the intermediaries would be adversely affected mainly due to investment performance of the TO (Kader et al., 2014).

Malaysia Takaful Association (MTA)'s 2020 Annual Report indicates that there are over 97,400 registered takaful agents. No aggregate figures are provided by the MTA or Bank Negara Malaysia of total takaful fees and commissions paid to intermediaries. While it is hard to quantify the total amount of contributions paid out in commissions to the intermediaries, the commission rates given to intermediaries are quite high according to Bank Negara Malaysia (2019). The following table, for example, demonstrates the maximum rates at which agents may be compensated for selling a policy according to BNM.

Table 1: Maximum percentage of annual premium/ contribution

\begin{tabular}{cccc}
\hline $\begin{array}{c}\text { Policy } \\
\text { Year }\end{array}$ & $\begin{array}{c}\text { Basic commissions for ordinary/ } \\
\text { corporate agents }\end{array}$ & $\begin{array}{c}\text { Overriding commissions for } \\
\text { agency leaders }\end{array}$ & $\begin{array}{c}\text { Total } \\
\text { commission }\end{array}$ \\
\hline 1 & $40 \%$ & $25 \%$ & $65 \%$ \\
2 & $30 \%$ & $10 \%$ & $40 \%$ \\
3 & $20 \%$ & $6 \%$ & $26 \%$ \\
4 & $15 \%$ & $5 \%$ & $20 \%$ \\
5 & $10 \%$ & - & $10 \%$ \\
6 & $10 \%$ & - & $10 \%$ \\
Total & $125 \%$ & $46 \%$ & $171 \%$ \\
\hline
\end{tabular}

Source: BNM (2019, p. 13)

Table 1 illustrates the share of contributions that are taken up only by the commissions to intermediaries, which does not include other operations and management expenses. Fintech potentially can help to reduce the operating costs, especially for marketing and sale purposes, and that will be discussed in detail in Section 3.

\subsection{The cost of fraudulent claims}

In reference to the Insurance Fraud Taskforce (2016), for instance, the value of detected fraudulent insurance claims exceeds $£ 1$ billion and undetected insurance fraud is estimated to cost the UK economy over $£ 2$ billion a year. Therefore, claim management for both conventional and Islamic insurance is a delicate task because it requires the timely claim processing and avoiding paying exaggerated or fraudulent claims at the same time (Malik and Ullah, 2019). Licensed surveyors engage experts to assess financial losses relating to vehicle, machinery and property damage when processing takaful claims. The authors will discuss how fintech could help to process claim in Section 3.

\section{The Role of Fintech in Takaful}

Fintech is abbreviation for financial technology and defined as "computer programs and other technology used to provide banking and financial services" (Oxford Learner's Dictionaries, 2021). This is done through the use specialised software and algorithms that are being used on different devices. The latter definition does not limit

International Journal of Management and Applied Research, 2021, Vol. 8, No. 2 
fintech to simply back-end activities but generalises its use to cases in all financial services. The commonly used fintech include P2P lending, crowdfunding, block chain and bitcoins, robo-advising, mobile payments and insurance. Each of these cases provides unique disruptive capabilities. In the case of improving cost-efficiency for takaful companies, this paper asserts that robo-advisory and big-data are two primary technologies that could achieve this end.

There has been shortage of fintech adoption among Islamic financial intermediaries generally, and by takaful operators in particularly. Equally, there have been limited studies conducted with the aim of uncovering the potential use of big data and roboadvisory in the context of cost-efficiency for takaful. Hence, the primary objective of this study is to elaborate on the ways in which big data and robo-advisors can reduce TO costs. This study applies a basic qualitative methodology in bringing to light the relevant details of the cost-saving potential of big data and robo-advisors using library research.

\subsection{Artificial Intelligence and Robo-Advisory}

Brenner and Meyll (2020) define robo-advisor as "automated financial advisor" whereas Baker and Dellaert (2017, pp. 719-720) define robo-advisor as "automated investment service, which competes with financial advisors by claiming to offer equally good, if not better, financial advice and service at a lower price". The idea behind the use of robo-advisor is about automating the financial advisory process and to make it faster, more accessible, flexible, convenient, and more importantly, costeffective. Other advantages of robo-advisory include objectivity and the reduction of human errors that could lead to substantial legal/regulatory costs for an organisation. Such level of efficiency is exactly what a TO needs.

Robo-advisor can be an effective cost-saving tool for TOs. Because of the availability to scale at the global level, AI-driven robo-advisors have the potential to provide greater quality and more accessible financial advice to more people at lower cost than human financial advisors (Baker and Dellaert, 2017). Moreover, robo-advisors can respond to behavioural changes and adapt to new needs based on algorithms that enable them to adapt.

\subsubsection{Advantages of AI and robo-advisors}

1. Objectivity: Since it is a computer program, robo-advice does not have self-interests, desires or hidden agenda, therefore its recommendations and decisions they come up with are considered to be objective and unbiased. The use of algorithms allows investment recommendations to be based on financial techniques and free from the behavioural bias of an advisor, resulting in objective recommendations for the client. As the automated advisors are based on complex algorithms, they can curate suitable insurance policy based on the risk tolerance and financial background of each individual customer. This not only could benefit potential customers in finding most suitable takaful plan but also takaful operator in reaching customers at different locations at the same time, without any conflict of interest (Baker and Dellaert, 2017).

2. Convenience: Robo-advisory is particularly suitable for clients who either have little time or no access to fund managers who typically charged handsomely for making investment portfolios. Unlike human agents, which are normally available only in their

International Journal of Management and Applied Research, 2021, Vol. 8, No. 2 
working hours, robo-advisors can respond to customer inquiry in real time. Roboadvisory is provided to consumers with little or no human intervention and takaful operators rely instead on computer-based algorithms (EIOPA, 2019). Based on financial information and investment objectives given by potential customers, roboadvisors could subsequently create an investment portfolio (Abraham et al., 2019; Brenner and Meyll, 2020; Jung et al., 2019) or takaful plan suitable for the customers. For existing customers, a robo-advisor, which manages their portfolio, could even reinvest surplus (Brenner and Meyll, 2020). In cases of risk or adverse changes in the market or other factors, robo-advisors keep clients updated regarding the takaful and other financial plans. Therefore, customers can develop a more hands-off approach while using robo-advisors.

4. Accessibility: robo-advisors are accessible via electronic devices, allowing potential and existing customers to access them on the $24 / 7$ basis as long as they have access to the Internet. Brenner and Meyll (2020) report the use of robo-advisors among US investors, and concluded that the technology-savviness and great accessibility of technological financial advisors are the underlying reasons for the users seeking financial advice from robo-advisors. This can be very helpful for takaful customers, especially in the case where the customers seek immediate responses when making claims.

5. Efficiency: The way an insurance agent interacts with the clients is time-consuming. In a traditional face-to-face setting, each financial advisor is responsible for a limited number of clients. Robo-advisor, on the other hand, can serve multiple clients concurrently. Unlike a human agent who is capable of handling only one communication a time, a robo-advisor can perform in a multitasking mode, which in the case of takaful can lead to increased efficiency as it can handle multiplicity of such tasks such as product inquiries, claim setup/inquiry, product advisory (FAQ), endorsement requests, policy renewal and others.

\subsubsection{Disadvantages of $A I$ and robo-advisors}

1. Lack of personalisation: Robo-advisors use automated algorithms and "one-size-fitall" questionnaires to make recommendations leading to financial decision; however these questionnaires and algorithms assume that individuals with similar financial background would have similar risk-taking behaviour or provide same answer to the same questions sought in questionnaires, which might not necessarily be true (Abraham et al., 2019). Additionally, the algorithms may be based on incorrect assumption or partial data which would affect the accuracy and relevancy of the recommendations. Trust tends to weaken in the event of automation error and may never fully recover (Bartlett and McCarley, 2019).

2. No personal contact: One of the biggest challenges of robo-advisory is that it lacks of human touch and/or emotions. Since robo-advisors are programmed they tend to be objective and therefore they often lacks the commonly found aspects of client-advisor relations such as sharing emotions during market volatility, counselling or helping customers to cope with grief (Abraham et al., 2019). A trusting client-advisory relation is particularly important for traditionally high net worth clients who value personal contact and trustworthiness of financial advisor (Jung et al. 2019).

International Journal of Management and Applied Research, 2021, Vol. 8, No. 2 
3. Manipulation: Robo-advisors are a product of the human mind and thus are susceptible to manipulation if their developers are left unchecked. After relying on the robo-advisory for a long time, an operator may experience the lack of skills necessary to intervene in system control when needed or ignore machine error (Bartlett and McCarley, 2019). The challenge for regulators is to facilitate an enabling environment promoting a diversified range of robo-advisors that can provide measurable quality financial advice and related services for consumers (Baker and Dellaert, 2018). As a mentioned earlier, robo-advisors are based on "one-size-fits-all" questionnaires which contribute to partial advice based on partial information. These questionnaires might not include questions such as future liabilities or spouse's financial conditions because they are not deemed to be relevant by the underlying algorithms or their developers (Abraham et al., 2019). As a tool, robo-advisory is not completely free from machine error. Users may not be able to notice and correct inadequate decisions made by roboadvisors (Bartlett and McCarley, 2019).

To sum up, takaful operator should take the merits and demerits of robo-advisory into consideration when making long-term strategic planning. Although robo-advisory is still at its early stage, it has a high potential in strengthening the operational efficiency of TOs. As Brenner and Meyll (2020) highlight, financial institutions should see roboadvisors as complementary rather than a substitute to human financial advice.

\subsection{Big Data Analytics}

In reference to IBM (n.d.), "Big data analytics is the use of advanced analytic techniques against very large, diverse big data sets that include structured, semistructured and unstructured data, from different sources, and in different sizes from terabytes to zettabytes-- such as hidden patterns, unknown correlations, market trends and customer preferences -- that can help organizations make informed business decisions".

According to EIOPA (2019), most insurance companies use the Big Data based algorithms in product development, pricing and underwriting stage of insurance, followed by claims management, and sales and distribution. The use of historical and behavioural data allows insurance companies to better understand their customers' needs and thus allow them to tailor customers' needs and offer more personalised services. In relation to that, insurance companies could accurately determine customer loyalty and organise marketing campaigns accordingly.

Big data can be broadly characterised by the availability of huge amounts of many different types of data from varied sources that could be processed rapidly. The Big Data phenomenon led to the development of a more sophisticated use of data analytics; it combines different digital technologies, such as artificial intelligence, to process and analyse aggregated data to estimate and support optimal decision-making based on these estimates (Ho et al., 2020). Data processing has traditionally been at the very core of insurance industry as insurance firms need to make quote, pricing, evaluate policyholders' claims and benefits, based on datasets such as demographic data and behavioural data (EIOPA, 2019). In the digital age, these datasets are slowly but increasingly combined with new set of data (e.g. geographical data and granular data) to predict and make informed decision based on these predictions.

International Journal of Management and Applied Research, 2021, Vol. 8, No. 2 
TOs have the choice, like in the case of robo-advisory, to develop their own in-house solutions for big data analytics, outsource, or purchase third party from technology firm like Statistical Analysis System (SAS). TO needs to consider the resources required to invest in algorithms and storage capacities that extend beyond their expertise. Buying off-shelf solution from a third party or outsourcing claims management to a third party is not uncommon in insurance industry, especially in the case where insurance companies seek to handle less administration and more on core business. Insurance companies that attempt to keep everything in-house typically built extensive duplication and redundancy across markets and businesses.

As with any industry, takaful operators need to continuously understand new technologies and understand how technological innovation can reshape the way operators do business. The potential use of big data in takaful industry will be discussed in the following section.

\subsubsection{Big Data for marketing}

To stay competitive in the market, takaful operators have had to understand and leverage the opportunities presented by technological change. In the past, advances in technology have slowly but significantly changed the way insurance firms reach their customers and consequently, how customers interact with insurance firms and maintain their loyalty. From electronic payments, to mobile applications, and "insurtech" (the combination of insurance and technology), insurance businesses and their clients are both constantly changing and adapting new technologies.

Takaful operators can take one step further ahead of social media marketing by using social media analytics (EIOPA, 2019) or actively engage customers in value cocreation process (Castriotta et al., 2013). Insurance companies have been using social media for marketing purposes (Castriotta et al., 2013) and pricing and underwriting purposes (EIOPA, 2019). Customers create value for companies when they promote particular firms or products via word-of-mouth, as well as provide their feedback on new services or identify possible improvements to existing offerings through social media (Castriotta et al., 2013). Companies, in turn, benefitted from word-of-mouth advertising as well as customer engagement. Personalised recommender systems are perceived as an improvement of coarse demographic targeting used in marketing.

Social media analytics would allow takaful operators to gather competitive intelligence such as understanding the effectiveness of marketing campaigns, customers' perception towards existing and new products. EIOPA (2019) reported that insurance companies mostly use social media analytics for counter-fraud services, alongside normal fraud detecting and processing, in order to help identify hidden links between claims. Another area of application is analysis of user behaviour for pricing and underwriting purposes (EIOPA, 2019).

\subsubsection{Big Data for claim management}

EIOPA (2019) reported that majority of insurance firms have been using big data analytics for claims management, especially in the area of automated payment processes, segmentation of claims, invoice verification, and most importantly, fraud detection. The use of big data analytics has been increasingly popular not only for

International Journal of Management and Applied Research, 2021, Vol. 8, No. 2 
insurance companies but also in law enforcement. For example, Durham Police in the UK solved the "cash for crash" scam which defrauded insurers by using big data intelligence analytics (Ward, 2014).

Takaful operators could deter, detect, record, and report fraud more effectively using big data analytics tools. Most insurance firms have leveraged on their historical data, in-house resources and their expertise in processing claims to develop their own big data analytics tools used in claims management (EIOPA, 2019). For example, machine learning algorithms trained to look for fraud patterns and flag potentially fraudulent claims for analysts to examine them further (Insurance Fraud Taskforce, 2016). Big data analytics tools support the detection of fraudulent claims in two common ways: first, insurance firms could cross-check information provided by potential customers prior to the conclusion of the contract to avoid scammers or fraudsters; second, firms could review document provided by the consumer to ensure damages claimed by the consumers are accurate (EIOPA, 2019).

Statistical Analysis System (SAS), a leading data analytics company conveniently summarises the claims fraud problem in the following diagram. Diagram 1 illustrates that fraudulent claims can be broadly categorised into two: premeditative and opportunistic. Big data analytics employ text mining based on social network analysis, predictive models, and anomaly detection. Organised crimes are premeditative and caused huge loss; for instance, the previously mentioned case where the Durham Police arrested criminal gang responsible for "cash for crash" scam worth around $£ 500,000$ million (Ward, 2014).

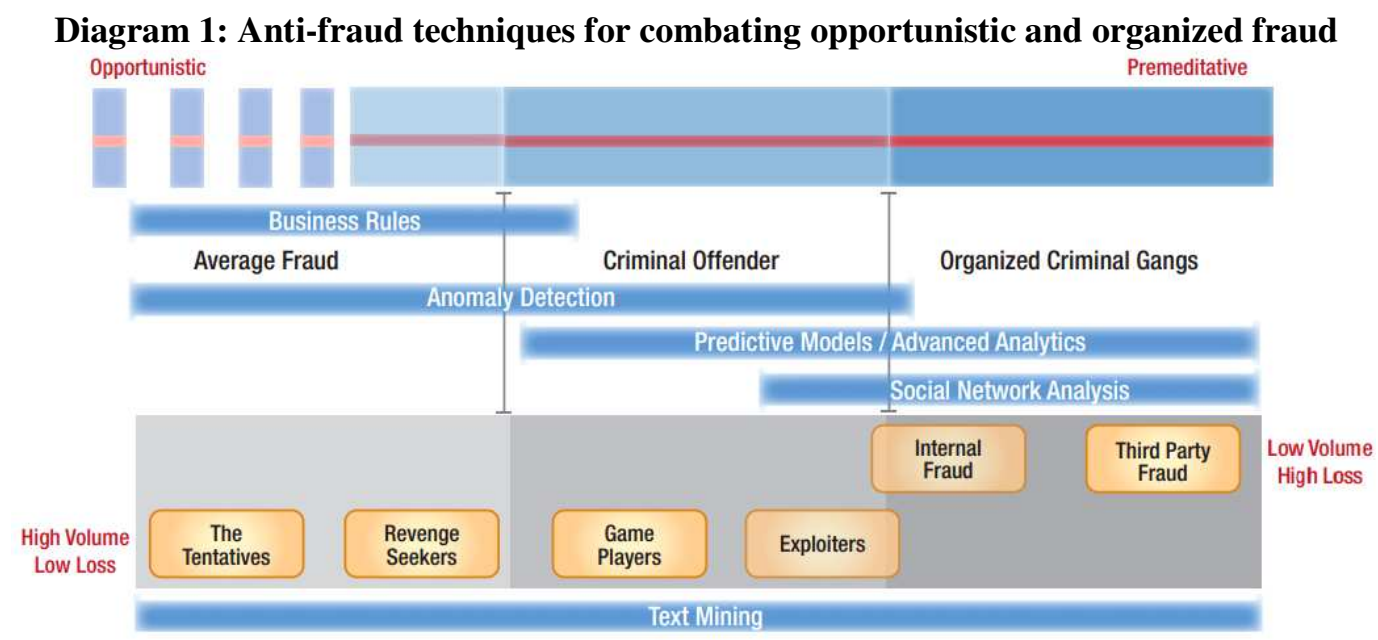

Source: SAS (2012, p. 3)

Traditional methods of claims investigation relied primarily on the human factor and human judgement. Big data analytics, through the use of AI and machine learning algorithms will allow for technology to speed up the investigation process. For instance, big data analytics tools could flag suspicious transactions or exaggerated claims (Insurance Fraud Taskforce, 2016).

In addition to traditional approaches to detect fraudulent claims (e.g. anomaly detection and business rules), big data analytics could allow higher level of data

International Journal of Management and Applied Research, 2021, Vol. 8, No. 2 
accuracy with the use of social network analysis, text mining, and predictive modelling (SAS, 2012). The use of social network analysis and text-mining allows insurance firms to cross-check evidence provided by the customers during the claims processing. Text mining uses a large amount of unstructured text, whereas social media analytics process both texts and non-textual data such as photos and videos that are published on social media platforms.

Like robo-advisory, big data analytics is useful for complementing, not substituting human analysts. Claim management often requires close human investigation and examination of the whole situation. In some cases, the claims processing will require a physical investigation to analyse the situation, taking pictures, interrogating anyone involved, assessing the police or medical reports as well as retain contact information for any individual who has witnessed the accident; all these will require the human involvement.

\subsubsection{Ethical concerns of using Big Data}

The use of big data analytics has raised some ethical and legal concerns related to interference with data handling and consumer rights. Entrusting a computer system or AI with sensitive data can be risky. The data may become vulnerable to its misuse and cyber security attacks. An ethical framework must be created to ensure consumers' rights are protected.

Like other for-profit corporations and social enterprises, takaful operators must always protect consumers' rights and be able to demonstrate compliance with the principle of accountability, that is, treat consumers fairly and transparently when processing personal data. In short, customers must be appropriately informed and takaful operators need to explain to their customers openly how data are collected and processed. The takaful operator-regulator relationship should be more collaborative in the digital age when harnessing the benefits of big data.

\section{Conclusion}

This paper explored the opportunities and challenges of using fintech in the takaful sector. More specifically, this paper analysed the potential use of big data analytics and robo-advisory in assisting takaful operators. TO can use big data analytics and roboadvisory for customer services including complaint management, post-sale services, pre-sale assistance, handling consumer queries, and consumer authentication. Big data analytics can help in addressing the problem of fraudulent claims which cost the insurance and takaful industries dearly. More importantly, TO would be benefitted from inclusion of AI in decision-making process, ranging from assessing claims to allocating resource strategically. Advantages of the use of big data analytics for TO include reduced operational costs and improved efficiency as a result of automating manual processes of filing paperwork as well as claims processing.

However, the use of big data analytics in insurance may cause legal and ethical concerns due to data security and privacy. Takaful operators must have adequate governance measures ensuring that consumers data are protected and must be able to demonstrate their compliance with personal data protection regulations.

International Journal of Management and Applied Research, 2021, Vol. 8, No. 2 
Fintech could play a beneficial role for takaful ecosystem, especially in equipping its workforce and strengthening Shariah governance. In particular, the authors of this paper recommend:

- Adopting robo-advisors would ensure that the existing and potential consumers appreciate services available around o'clock. Takaful operators would benefit from increased efficiency and reduced operational costs in long run compared to the traditional methods of providing face-to-face advice. However, there could be possible technical errors or functional limitations in the design of the robo-advisors, especially in the context of takaful and the complexities revolving around Shariah compliance.

- Developing and building big data analytics algorithms: big data analytics tools can be used as support for regular analytical work, such as to flag potentially fraudulent claims, with all outputs being reviewed by human analysts as part of claims processing. Nonetheless, developers and users of big data analytics tools need to ensure that big data analytics is applied in ways that meet ethical standards and regulatory frameworks.

The current legislation is only a baseline, policy guidance and governance mechanisms are required to do more in meeting higher ethical standards of protecting consumers in this constantly evolving area. Policymakers not only need to consider the longitudinal impact of big data analytics on consumer rights, but also provide conducive environment for the development of AI, particularly where technological advances are slowly but increasingly adopted by big corporations. Takaful regulators, similarly, need to monitor the development of AI and shape an enabling environment for creation of trustworthy AI.

Future studies could explore the perception of TO regarding their views towards the application of AI in takaful, especially perceived opportunities and barriers, as well as likelihood of adopting big data analytics and robo-advisors. In relation to that, researchers should further examine consumers' perception towards robo-advisors in different cultural settings.

\section{References}

1. Abraham, F.; Schmukler, S. L. and Tessada, J. (2019), "Robo-Advisors: Investing through Machines", Research \& Policy Briefs From the World Bank Chile Center and Malaysia Hub, [Online] Available from: https://documents1.worldbank.org/curated/en/275041551196836758/pdf/RoboAdvisors-Investing-through-Machines.pdf [Accessed on 5 February 2021].

2. Archer, S., Karim, R. A. A., and Nienhaus, V. (Eds.), (2011), Takaful Islamic insurance: Concepts and regulatory issues, Singapore: John Wiley \& Sons. https://doi.org/10.1002/9781118390528

3. Bank Negara Malaysia (BNM) (2019), Operating cost controls for life insurance and family takaful business, [Online] available at: https://www.bnm.gov.my/documents/20124/761679/pd_occforlifeandfamilytakaful

International Journal of Management and Applied Research, 2021, Vol. 8, No. 2 
business +dec2019.pdf/d1486cfb-63e2-6fd2-7b7d-

$\underline{6 c 8 e 30569 b f 2 ? t=1578648660074}$ [Accessed on 4 October 2020].

4. Baker, T. and Dellaert, B. (2017), "Regulating robo advice across the financial services industry", Iowa Law Review, Vol. 103, pp. 713-750

5. Bartlett, M.L. and McCarley, J.S. (2019), "Human interaction with automated aids: Implications for robo-advisors", Financial Planning Review, Vol. 2, No. 3-4, e1059. https://doi.org/10.1002/cfp2.1059

6. Bekkin, R. I. (2007), "Islamic Insurance: National Features and Legal Regulation", Arab Law Quarterly, Vol. 21, No. 1, pp. 3-34. https://doi.org/10.1163/026805507X197820

7. Brenner, L. and Meyll T. (2020), "Robo-advisors: A substitute for human financial advice?", Journal of Behavioral and Experimental Finance, Vol. 25, 100275. https://doi.org/10.1016/j.jbef.2020.100275

8. Castriotta, M., Floreddu, P.B., Di Guardo, M.C. and Cabiddu, F. (2013), "Disentangling the Strategic Use of Social Media in the Insurance Industry: A Value Co-Creation Perspective", in: Social Media in Strategic Management: Advanced Series in Management, Vol. 11, Bingley: Emerald Group Publishing Limited, pp. 63-86. https://doi.org/10.1108/S1877-6361(2013)0000011008

9. European Insurance and Occupational Pensions Authority (EIOPA) (2019), Big Data Analytics in Motor and Health Insurance: A Thematic Review, Luxembourg: Publications Office of the European Union.

10. Hassan A. and Mollah S. (2018), "Operational Mechanism of Takaful and ReTakaful", In: Islamic Finance. Palgrave Macmillan, Cham. https://doi.org/10.1007/978-3-319-91295-0_14

11. Ho, C.; Ali, J. and Caals, K. (2020), "Ensuring trustworthy use of artificial intelligence and big data analytics in health insurance", Bulletin of the World Health Organization, Vol. 98, pp.263-269. https://doi.org/10.2471/BLT.19.234732

12. IBM (n.d.), Big data analytics, [Online] Available from: https://www.ibm.com/uken/analytics/hadoop/big-data-analytics [Accessed on 3 April 2021].

13. Insurance Fraud Taskforce (2016), Insurance Fraud Taskforce: final report, [Online] available from: https://assets.publishing.service.gov.uk/government/uploads/system/uploads/attach ment data/file/494105/PU1817 Insurance Fraud Taskforce.pdf [Accessed on 3 April 2021].

14. Islamic Financial Services Board (IFSB) (2009), Guiding Principles on Governance for Takaful Undertakings. [Online] Available from:

International Journal of Management and Applied Research, 2021, Vol. 8, No. 2 
https://www.ifsb.org/download.php?id=4364\&lang=English\&pg=/published.php [Accessed on 3 April 2021].

15. Iqbal, M. (2005), General Takaful Practice: Technical Approach to Eliminate Gharar (uncertainty), Maisir (gambling), and Riba' (usury), Jakarta: Gema Insani.

16. Jung D.; Glaser F. and Köpplin W. (2019), "Robo-Advisory: Opportunities and Risks for the Future of Financial Advisory", In: Nissen V. (eds), Advances in Consulting Research. Contributions to Management Science, Cham: Springer. pp 405-427. https://doi.org/10.1007/978-3-319-95999-3_20

17. Kader, H. A.; Adams, M.; Hardwick, P. and Kwon, W. J. (2014), "Cost efficiency and board composition under different takaful insurance business models", International Review of Financial Analysis, Vol. 32, pp. 60-70, https://doi.org/10.1016/j.irfa.2013.12.008

18. Kadirov, D. (2021), "Marketing Islamic services: tackling misconceptualisation of commercial insurance", Journal of Islamic Marketing, Vol. 12 No. 2, pp. 264-279. https://doi.org/10.1108/JIMA-08-2019-0172

19. Malaysia Takaful Association (2018), Annual Report 2020, available from https://www.malaysiantakaful.com.my/sites/default/files/mta-annual-reportfinal.pdf [Accessed on 2 October 2019].

20. Malik A. and Ullah K. (2019), Introduction to Takaful. Singapore: Palgrave Pivot, https://doi.org/10.1007/978-981-32-9016-7

21. Oxford Learner's Dictionaries (2021), fintech, Oxford University Press, [Online] Available from: https://www.oxfordlearnersdictionaries.com/definition/english/fintech [Accessed on 6 March 2021].

22. Saputra, J., Kusairi, S. and Sanusi, N. (2017), "Modeling the Premium and Contract Properties of Family Takaful (Islamic Life Insurance)", Journal of King Abdulaziz University: Islamic Economics, Vol. 30, No. 2, pp. 135-157. https://doi.org/10.4197/Islec.30-2.12

23. SAS (2012), Combating insurance claims fraud (White Paper), [Online] Available from: $\quad$ https://support.sas.com/resources/papers/proceedings12/105573 0212.pdf [Accessed on 16 October 2019].

24. Ward, M. (2014), "Crime fighting with big data weapons", $B B C$ [Online] Available from: https://www.bbc.co.uk/news/business-26520013 [Accessed on 2 October 2019].

International Journal of Management and Applied Research, 2021, Vol. 8, No. 2 